\title{
Bone Marrow Transplantation Demonstrates That Carbonic Anhydrase II Deficiency Limited to Bone Marrow-Derived Cells Affects Ammonium Chloride Tolerance in Mice
}

\author{
Leslie G. Biesecker, ${ }^{*}$ Robert P. Erickson, ${ }^{*}+, 1$ and Richard E. Tashian ${ }^{\dagger}$ \\ Departments of *Pediatrics and $†$ Human Genetics, University of Michigan Medical School, Ann Arbor, Michigan 48109
}

Received August 30, 1993

\begin{abstract}
Bone marrow transplantation (BMT) in mice was utilized to determine the relative importance of carbonic anhydrase II (CA II) deficiency in blood compared to kidney in the pathogenesis of the ammonium chloride intolerance observed in CA IIdeficient mice. "Normal" BMT experiments utilized normal donors and $\mathrm{CA}$ II-deficient recipients (NL $\rightarrow$ DEF), "reverse" BMT experiments utilized CA II-deficient donors and normal recipients, and control BMT experiments utilized normal mice with a hemoglobin polymorphism ( $\mathrm{Hbb} \mathrm{d} / \mathrm{s}$ ). Unstressed urinary pH was not significantly altered by normal or reverse BMT, nor was any change induced by control BMT. However, DEF $\rightarrow$ NL mice showed markedly altered weight changes when placed on oral ammonium chloride, an effect apparently secondary to dehydration due to decreased water intake. In addition, some CA II-deficient mice have a urinary concentrating defect. Red blood cell and kid. ney CA II deficiency contribute additively to these effects. $O 1994$ Academic Press, Inc.
\end{abstract}

The carbonic anhydrases (EC 4.2.1.1) catalyze the reversible hydration of $\mathrm{CO}_{2}$ and occupy key roles in such physiological processes as acid-base equilibrium, $\mathrm{CO}_{2}$ and ion transport, and secretion $(1,2)$. Currently, eight isozymes of carbonic anhydrase or carbonic anhydrase-like proteins are known to occur in mammals and they differ in distribution and activity (2-5). Of these, carbonic anhydrase II (CA II) has the highest specific activity and the widest

\footnotetext{
${ }^{1}$ Current address: Steele Memorial Children's Research Center, Departments of Pediatrics and Molecular and Cellular Biology, University of Arizona Health Science Center, Tucson, AZ 85724 .
}

tissue distribution (2). Deficiency of CA II in humans leads to the autosomal recessive disorder, carbonic anhydrase deficiency syndrome, which is characterized by osteopetrosis, renal tubular acidosis (RTA), and central nervous system calcifications (68).

A murine model of carbonic anhydrase II deficiency has been created utilizing an $N$-ethyl- $N$-nitrosourea-induced mutation in a male DBA/2J animal (9). The mouse model manifests RTA and diffuse subendothelial calcifications of blood vessels, but not osteopetrosis or central nervous system calcifications (9-11). Despite the complete deficiency of CA II, which is normally at high levels in oligodendrocytes, glial cells are morphologically normal (12). Renal tubular acidosis has been inferred to be present by urine alkalinity and reduced serum bicarbonate concentration, and ammonium chloride has been reported to induce weight loss in these animals by induction of systemic acidosis (9). Much discussion has centered on the relative contributions of CA II present in blood cells (mostly erythrocytes), compared to renal and endothelial cells in the RTA and subendothelial calcifications, respectively $(10,13)$. Brechue et al. (14) have demonstrated that cytosolic, but not membrane associated, $\mathrm{CA}$ is lacking in CA II-deficient mice, and that the latter is the major contributor to proximal tubule $\mathrm{HCO}_{3}$ reabsorption. These data support the hypothesis that renal CA (specifically membrane-associated $\mathrm{CA}$ ) is more important for $\mathrm{pH}$ regulation than erythrocyte $\mathrm{CA}$. However, a major role for erythrocyte carbonic anhydrase in total body $\mathrm{pH}$ regulation has been clearly demonstrated in fish $(15,16)$, suggest- 
ing either that CA plays a different role in fish or that erythrocyte CA II has additional, as yet unappreciated, effects in mammals.

Bone marrow transplantation allows separation of the effects of kidney and erythrocyte CA II deficiency to address these questions by replacing the hematopoietic compartment of deficient animals with CA II-normal cells and normal animals with deficient cells. An animal can be transplanted to have CA II-deficient blood cells with the solid tissues having normal CA II activity or with CA II-normal blood cells and CA II-deficient solid tissues. The first approach, referred to as "normal" bone marrow transplantation, was to determine the effects of a correction of erythrocyte CA II deficiency by transplantation of normal bone marrow into CA II-deficient recipients (NL $\rightarrow \mathrm{DEF})$. The second approach, referred to as "reverse" bone marrow transplantation, was to transplant CA II-deficient bone marrow into normal animals (DEF $\rightarrow \mathrm{NL}$ ) to study the effect of abnormal erythrocyte CA II metabolism in the milieu of normal kidney CA II.

\section{MATERIALS AND METHODS}

Mice. Animals used in these studies were either CA II-deficient or normal B6D2F1 (C57BL/6 $\times$ DBA/2J F1 offspring). The CA II-deficient mouse strain is derived by random breeding from the B6D2F1 animal detected by Lewis et al. (9).

Phenotype assay. All testing for erythrocyte CA II protein was performed by double-diffusion immunoprecipitation with an anti-CA II antibody on washed red blood cells obtained by tail bleeding (9). Presence of any precipitation was scored as positive; absence of visually detectable precipitation was scored as negative. The lower limit of sensitivity was $1-2 \%$ of normal (data not shown). Hemoglobin b (Hbb) typing was performed by the method of Whitney (17) which differentiates the codominant single (s) Hbb type from the diffuse (d) Hbb type.

Bone marrow transplantation. Bone marrow donors were either CA II-/-, normal B6D2F1, or CA II enzyme-positive littermates of CA II-deficient animals. Recipients were either CA II-/-, or normal B6D2F1. In order to control for the effects of transplantation and graft versus host disease, controls were designed to transplant normal marrow into normal animals. Control bone marrow transplant (BMT) donors were $\mathrm{C} 57 \mathrm{BI} / 6 \mathrm{Hbb} / \mathrm{s}$ and recipients were B6D2F1 $\mathrm{Hbb} d / d$. Recipients were conditioned on the day preceding transplantation with 650-750 rads of X-irradiation and on the day of transplantation with $325-375$ rads from a ${ }^{137} \mathrm{Ce}$ source (JL Shepard) at a rate of $168 \mathrm{rads} / \mathrm{min}$. The bone marrow was flushed into a sterile microcentrifuge tube with a 21-gauge needle containing sterile phosphate-buffered saline. The cell concentration was adjusted to allow injection of $1-2 \times 10^{6}$ cells/animal via tail vein. The animals were retested for erythrocyte CA II or hemoglobin isotype at Day 90-180 post-transplantation.

Determination of renal acidification of urine. Urinary $\mathrm{pH}$ was determined by expressing urine onto wax film and tested either directly with $\mathrm{pH}$ indicator strips (Colorphast, accurate to $0.5 \mathrm{pH}$ unit) or transferred to a $10 \times 75-\mathrm{mm}$ glass tube and tested immediately with a $\mathrm{pH}$ probe (Corning). Unstressed $\mathrm{pH}$ was performed on urine from animals drinking normal tap water and fed mouse chow ad libitum (Purina). Normal tap drinking water was replaced with solutions of 1.5 and $0.7 \%$ ammonium chloride (Merck), or animals were fed a solution of $0.8 \%$ ammonium chloride and $0.5 \%$ sucrose (Sigma) without solid food to induce acid ingestion. These animals were weighed daily to determine weight loss during acidification. Specific gravity of expressed urine was determined by freezing point depression. This study was reviewed and approved by the University Committee for the Use and Care of Animals.

\section{RESULTS}

Eleven CA II-deficient animals were transplanted with normal bone marrow (NL $\rightarrow$ DEF). Of these 11 , 6 survived and 4 of those tested positive for erythrocyte CA II and 2 tested negative (67\% engraftment). Thirty-four normal animals were transplanted with CA II-deficient bone marrow $(\mathrm{DEF} \rightarrow \mathrm{NL})$ and 19 survived. Of these 19 survivors, 12 tested negative for erythrocyte CA II (63\% engraftment). The hemoglobin polymorphism transplant control group (NL $\rightarrow \mathrm{NL}$ ) comprised 13 animals of which 10 survived, all of whom were engrafted with donor marrow, according to hemoglobin polymorphism. The survival rates in the NL $\rightarrow$ DEF $(54 \%)$ and DEF $\rightarrow \mathrm{NL}$ (56\%) groups were lower than those in the $\mathrm{NL} \rightarrow \mathrm{NL}$ animals $(77 \%)$. The increased survival rate in the NL $\rightarrow$ NL animals was presumably due to syngeneic $\mathrm{H}-2$ tissue matching leading to decreased graft versus host disease. The engraftment rate among survivors was similar in the 


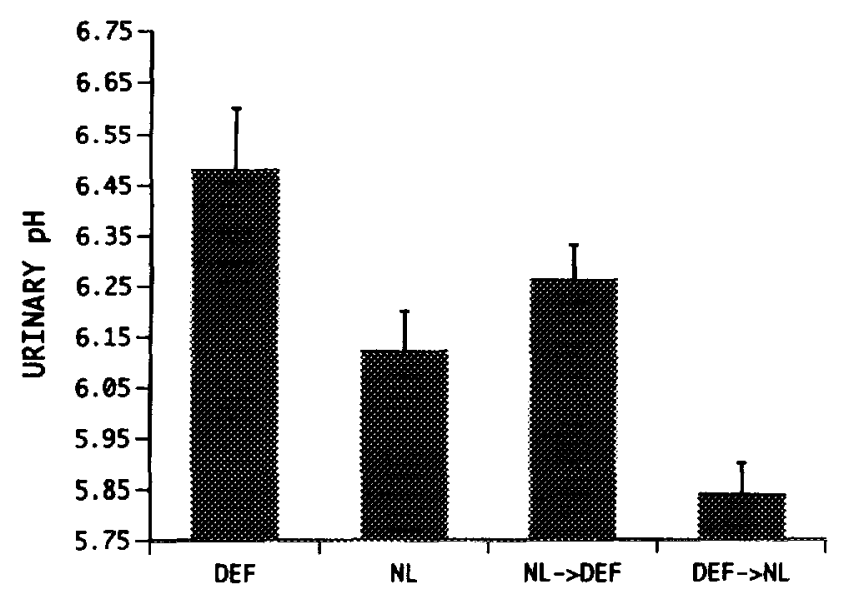

FIG. 1. Urine $\mathrm{pH}$ of animals drinking tap water. The $\mathrm{pH}$ of manually expressed urine was measured with a standard $\mathrm{pH}$ probe. The four groups are: DEF, CA II deficient, NL, normal; $\mathrm{NL} \rightarrow \mathrm{DEF}, \mathrm{CA}$ II deficient animals transplanted with normal bone marrow; DEF $\rightarrow$ NL, normal animals transplanted with bone marrow from CA II-deficient animals. The $\mathrm{pH}$ of urine from deficient animals was significantly lower than normals $(P<$ 0.02). The urine $\mathrm{pH}$ of the transplanted animals was not significantly different from that of normal animals.

$\mathrm{DEF} \rightarrow \mathrm{NL}$ and NL $\rightarrow$ DEF groups and approximately half that of the $\mathrm{NL} \rightarrow \mathrm{NL}$ transplanted animals, again presumably due to decreased rejection.

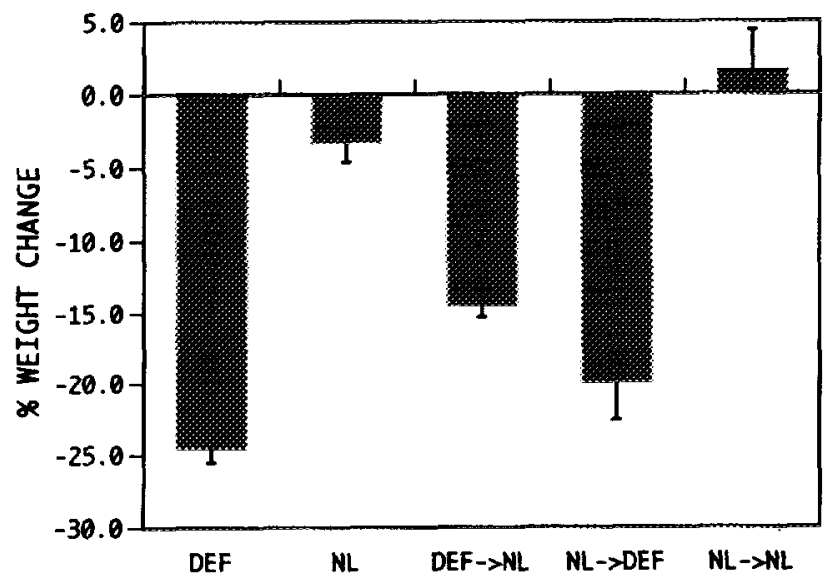

FIG. 2. Weight loss of animals fed acidified water. Groups are as described in the legend to Fig. 1 with the addition of $\mathrm{NL} \rightarrow \mathrm{NL}$, which is a control group of normal animals transplanted with normal bone marrow. Animals were fed a normal diet of solid food, but a $1.5 \%$ solution of ammonium chloride was substituted for the usual drinking water. The deficient animals lost significantly more weight than normals $(P<0.0001)$. Normal animals transplanted with deficient marrow $(\mathrm{DEF} \rightarrow \mathrm{NL})$ had an intermediate weight loss, which was significantly greater than that of NL $\rightarrow \mathrm{NL}$ controls $(P<0.005)$. There was no significant difference between DEF and NL $\rightarrow$ DEF animals.

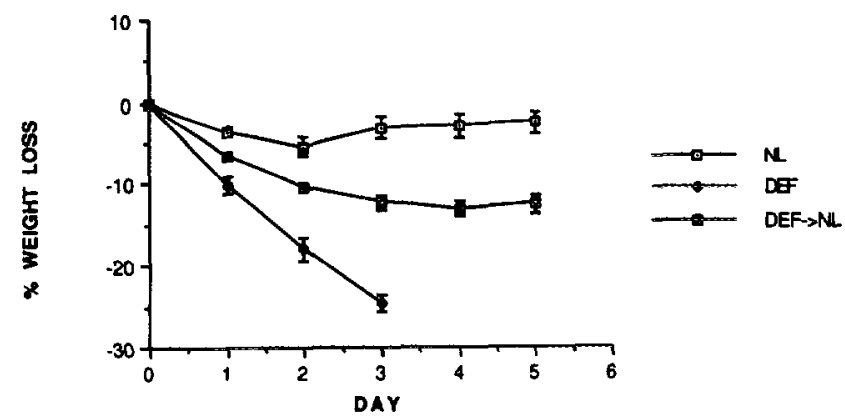

FIG. 3. Time course of weight loss effect. Conditions are as described in the legend to Fig. 2. Weight loss in normal animals was minimal and in deficient animals was severe. The experiment was discontinued in the deficient animals at Day 3, because it was unlikely they would survive another day based on their clinical condition. Normal animals transplanted with deficient marrow had an intermediate weight loss effect, demonstrating the contribution of blood cell CA II deficiency to this effect. Vertical barg indicate 1 SE.

The average urinary $\mathrm{pH}$ for nontransplanted $\mathrm{CA}$ II-deficient animals fed tap water (Fig. 1) was 6.48 \pm 0.12 (SE) and for nontransplanted B6D2F1 animals was $6.12 \pm 0.08(P<0.02)$ (two-tailed Student's $t$ test (18)), confirming previous results $(9,14)$. The urinary $\mathrm{pH}$ of $\mathrm{NL} \rightarrow \mathrm{DEF}$ transplanted animals was $6.26 \pm 0.07$ which was not significantly lower than that of the CA II-deficient animals, suggesting that the BMT did not affect the urinary $\mathrm{pH}$ of these animals. Similarly, the DEF $\rightarrow$ NL transplanted animals had an average urinary $\mathrm{pH}$ of $5.84 \pm 0.06$, which was actually lower, but not significantly so, than the control B6D2F1 animals.

The animals were then stressed with acidified water (Fig. 2). CA II-deficient mice lost $24.5 \pm 1.0 \%$ of initial body weight at 3 days post-acid load while B6D2F1 mice lost $3.2 \pm 1.4 \%(P<0.0001)$. B6D2F1 and CA II-positive mice transplanted with CA IIdeficient bone marrow (DEF $\rightarrow \mathrm{NL}$ ) lost $14.4 \pm 0.9 \%$ of body weight $(P<0.0005$ compared to $\mathrm{NL} \rightarrow \mathrm{NL}-$ transplanted animals). The typical time course of weight loss in normal animals was a drop of 5-10\% in the first several days, followed by partial recovery or net growth by 5 days (Fig. 3). Mice deficient in CA II have a steep decline in weight such that the experiments had to be terminated at 3 days because of the possibility of death from dehydration. The $\mathrm{DEF} \rightarrow \mathrm{NL}$ transplanted animals manifested an intermediate weight loss effect. The weight loss of the four NL $\rightarrow$ DEF-transplanted animals was $19.9 \% \pm$ $2.7 \%$, not significantly different than the non-transplanted deficient animals. The control transplanted 
animals gained $1.5 \% \pm 2.9 \%$ of body weight, which is not different from the control nontransplanted animals.

Observations of the acid-containing water bottles led us to suspect that the mice were drinking very little, if any, of the acidified water. The control animals ingested less than $0.025 \mathrm{cc} / \mathrm{g}$ body wt/day of the acidified water and the deficient animals ingested less than $0.001 \mathrm{cc} / \mathrm{g}$ body wt/day. This intake was clearly inadequate and suggested that the weight loss effect was due mainly to decreased water intake. To determine if this effect was due to concentrating ability we tested the urine osmolality of the animals. Urine osmolality of control animals drinking tap water was $2256 \pm 25 \mathrm{mOsm} /$ liter and for CA II-deficient animals was $1958 \pm 125$ $\mathrm{mOsm} /$ liter $(P>0.05)$. It is interesting to note that although the groups were not statistically different, the distribution of osmolality values was quite different in the two groups, with half of the deficient animals having values below $2100 \mathrm{mOsm} / \mathrm{liter}$. The urine osmolality for $\mathrm{DEF} \rightarrow \mathrm{NL}$-transplanted animals was $2338 \pm 31 \mathrm{mOsm} / \mathrm{liter}(P>0.05 \mathrm{com}$ pared to controls).

\section{DISCUSSION}

The relative effect of tissue compared to erythrocyte CA II deficiency in RTA has been debated previously. Whyte et al. (13) reported a woman with CA II deficiency who required a massive transfusion due to uterine hemorrhage who did not evidence changes in renal function despite expression of CA II activity in peripheral blood. This clinical situation provided an opportunity to study the short-term effects of a conversion of deficient to normal erythrocyte CA II activity and suggested that erythrocyte CA II deficiency did not contribute to the RTA manifested in this patient. Bone marrow transplantation has been performed in a child with clinical signs of CA II deficiency (19). The transplant was shown not to affect the RTA at 18 months post-transplantation although there was improvement in the osteopetrosis. This patient has not been tested for CA II deficiency and therefore conclusions based on this single case are not definitive.

Our experiments were designed to evaluate the relative contribution of kidney versus erythrocyte CA II deficiency in the murine CA II deficiency model. Corrective BMT in CA II-deficient mice was performed to test the effect of normal erythrocyte CA II activity in animals otherwise deficient in CA
II. The second approach was to transplant CA IIdeficient bone marrow into normal mice to test the effect of deficient erythrocyte CA II activity in animals with normal CA II activity in all other tissues. The results demonstrate that conversion of erythrocyte CA II activity is achievable in mice with BMT. Normal mice transplanted with CA II-deficient bone marrow (DEF $\rightarrow \mathrm{NL}$ ) have no detectable CA II protein in peripheral blood and CA II-deficient mice transplanted with normal bone marrow (NL $\rightarrow \mathrm{DEF}$ ) are positive for CA II in peripheral blood. The urinary $\mathrm{pH}$ in NL $\rightarrow \mathrm{DEF}$ animals did not improve following BMT, nor was there an induction of urine alkalinity in DEF $\rightarrow \mathrm{NL}$ animals. These data suggest that the RTA of CA II deficiency is not affected by BMT, in agreement with previous human data $(13,19)$. To further address the question of acid-base physiology, ammonium chloride was added to the drinking water, which had been reported (9) to induce severe weight loss in CA II-/animals. Further investigation of this weight loss effect has led us to conclude that the effects previously attributed to ammonium chloride ingestion are largely due to water deprivation as the animals drink very little of this water. A contributing mechanism for this effect may be that the animals have an aversion to acidified water and therefore do not drink a normal amount of acidified water and that CA II-deficient animals lose more weight than do controls, due an enhanced aversion to the acidified water and/or a reduction in the ability to concentrate their urine in the face of severe water deprivation. It is interesting to note that the deficient animals were heterogeneous in concentrating ability with two of the older animals unable to increase urine osmolality above $1850 \mathrm{mOsm} /$ liter while all of the control animal urine osmolalities were greater than $2100 \mathrm{mOsm} /$ liter.

The data demonstrate that normal animals transplanted with CA II-deficient bone marrow have an intermediate weight loss on acidified water (water deprivation), but do not manifest a statistically significant decrement of urine osmolality when compared to the control animals. Thus urinary concentrating ability alone does not explain the intermediate effect seen in the DEF $\rightarrow$ NL-transplanted animals. We conclude that erythrocyte and kidney CA II additively contribute to resistance to the weight loss effect and that this weight loss effect is partially explained by urinary concentrating ability. It is posssible that the erythrocyte CA II deficiency may cause aversion to acidified water via 
heightened sensitivity (perhaps mediated by taste) to $\mathrm{pH}$ changes in drinking water. In summary, BMT is a powerful technique for studying the pathogenesis of CA II deficiency as it allows separation of the effects of circulating erythrocyte CA II from that present in the kidney. Water deprivation causes severe weight loss in CA II-deficient mice and this effect can be induced in normal animals via BMT. These results suggest that erythrocyte CA II plays a significant role in the weight loss effect, perhaps via an effect on taste receptors or CNS responses to the acid taste.

\section{ACKNOWLEDGMENTS}

The authors thank Ya-Shiou L. Yu for expert technical assistance. This work was supported by National Institutes of Health Developmental Biology Training Grant T32 HDO727405 (LGB), University of Michigan Phoenix Memorial Award No. 715 (LGB), and National Institutes of Health Grants HD 26454 (RPE) and GM-24681 (RET).

\section{REFERENCES}

1. Dodgson SJ, Tashian RE, Gros G, Carter ND (Eds.) The Carbonic Anhydrases: Cellular Physiology and Molecular Genetics. New York: Plenum, 1991.

2. Tashian RE. The carbonic anhydrases: Widening perspectives on their evolution, expression and function. BioEssays 10:186-192, 1989.

3. Hewett-Emmet D, Tashian RE. Structure and evolutionary origins of the carbonic anhydrase multigene family. In The Carbonic Anhydrases: Cellular physiology and Molecular Genetics (Dodgson SJ, Tashian RE, Gros G, Carter ND, Eds.). New York: Plenum, 1991, pp 15-32.

4. Kato K. Sequence of a novel carbonic anhydrase-related polypeptide and its exclusive presence in purkinje cells. FEBS Lett 271:137-140, 1990.

5. Amor-Gueret $\mathbf{M}$, Levi-Strauss $M$. Nucleotide and derived amino-acid sequence of a cDNA encoding a new mouse carbonic anhydrase. Nucleic Acids Res 18:646, 1990.

6. Sly, WS, Hewett-Emmett D, Whyte MP, Yu YL, Tashian RE. Carbonic anhydrase II deficiency identified as the primary defect in the autosomal recessive syndrome of osteopetrosis with renal tubular acidosis and cerebral calcification. Proc Natl Acad Sci USA 80:2752-2756, 1983.
7. Sly WS, Whyte MP, Sundaram V, Tashian RE, HewettEmmett D, Guibaud P, Vainsel M, et al. Carbonic anhydrase II deficiency in 12 families with the autosomal recessive syndrome of osteopetrosis with renal tubular acidosis and cerebral calcifications. $N$ Engl J Med 313:139-145, 1985.

8. Sly, WS. The carbonic anhydrase II deficiency syndrome: Osteopetrosis with renal tubular acidosis and cerebral calcification. In The Metabolic Basis of Inherited Disease (Scriver CR, Beaudet AL, Sly WS, Valle D, Eds.). New York: McGraw-Hill, 1989, pp 2857-2866.

9. Lewis SE, Erickson RP, Barnett LB, Venta PJ, Tashian RE. $N$-Ethyl- $N$-nitrosourea-induced null mutation at the mouse Car-2 locus: An animal model for human carbonic anhydrase II deficiency syndrome. Proc Natl Acad Sci USA 85:1962-1966, 1985.

10. Spicer SS, Lewis SE, Tashian RE, Schulte BA. Mice carrying the Car-2 null allele lack carbonic anhydrase II immunohistochemically and show vascular calcification. Am J Pathol 134:947-954, 1989.

11. Jepsen KJ, Goldstein SA, Biesecker LG, Spicer SS, Erickson RP. The mechanical properties of cortical bone from carbonic anhydrase II deficient mice. Am J Hum Genet 47:A159, 1990.

12. Ghandour MS, Skoff RP, Venta PJ, Tashian RE. Oligodendrocytes express a normal phenotype in carbonic anhydrase II-deficient mice. J Neurosci Res 23:180-190, 1989.

13. Whyte MP, Hamm LL, Sly WS. Transfusion of carbonic anhydrase-replete erythrocytes fails to correct the acidification defect in the syndrome of osteopetrosis, renal tubular acidosis, and cerebral calcifications (carbonic anhydrase-II deficiency). J Bone Min Res 3:385-388, 1988.

14. Brechue WF, Kinne-Saffran E, Kinne RKH, Maren TH. Localization and activity of renal carbonic anhydrase (CA) in CA-II deficient mice. Biochim Biophys Actc 1066:201207, 1991.

15. Motais R, Fievet B, Garcia-Romeau F, Thomas S. $\mathrm{Na}^{+}-\mathrm{H}^{+}$ exchange and $\mathrm{pH}$ regulation in red blood cells: Role of uncatalyzed $\mathrm{H}_{2} \mathrm{CO}_{3}$ dehydration. Am $J$ Physiol 256:C728, 1989.

16. Cossins A. Regulation by fish red cells. Nature 340:20, 1989 .

17. Whitney JB III. Simplified typing of mouse hemoglobin (Hbb) phenotypes using cysteamine. Biochem Genet 16:667672, 1978.

18. Mould RF. Introductory Medical Statistics. Bristol: Adam Hilger/IOP, 1989.

19. Ballet JJ, Griscelli C, Coutris C, Milhaud G, Maroteaux P. Bone-marrow transplantation in osteopetrosis. Lancet 2(8048):1137, 1977. 